\title{
On a wing and a prayer
}

\section{This issue's focus on avian flu highlights progress and incoherence in the world's response to a potential human pandemic. But the threat is enormous, and some priorities are clear enough.}

$1 /$ illions of people killed in highly developed countries within months. Tens of millions worldwide. The global economy in tatters. A Hollywood fantasy? No - it's now a plausible scenario. The first act, the spread of avian flu to, and probably between, humans, has already started across Asia. Unless the international community now moves decisively to mitigate this pandemic threat, we will in all probability pay heavily within a few years. Then, hard questions will be asked as to why we were not prepared.

Sceptics abound, convinced that talk of a pandemic must be scaremongering, or scientists crying wolf. Surely with support care, drugs and vaccines, at least the rich world can easily stand up to a flu virus? After all, this is 2005 , not 1918 , when a flu pandemic killed up to 50 million people worldwide. But while the science and medicine of flu have advanced substantially, our ability to mount an effective public-health response has made remarkably little progress over the decades, and the potential for panic is, if anything, greater given the impact of television and the Internet.

In the 1918 pandemic, no one had immunity to a new subtype of

"While the science and medicine of flu have the influenza virus. The maths of epidemiology says that pandemics are like fault lines: they inevitably give. But unlike earthquakes, pandemics tend to give warning signs, and all the alerts from Asia are now flashing red. Will it be the 'big one'? No one can say with certainty, but the H5N1 flu strain now circulating widely in Asia, and several of its advanced substantially, our ability to mount an effective publichealth response has made remarkably little progress." cousins, are ones to which we humans have no immunity. Accordingly, the world now needs to develop defences for the worst-case scenario. How prepared are we?

Extinguishing avian flu in poultry and pigs, the melting-pot from which a pandemic strain would probably emerge, is the job of national agriculture and veterinary departments, the United Nations' Food and Agriculture Organization, and the World Organisation for Animal Health (OIE). The public-health aspects are the responsibility of health departments and the World Health Organization (WHO). This international coalition is shaky and far from united or sure in its purpose. Its efforts are grossly underfunded, and undermined at every turn by conflicts between global public health, sovereignty and the stakes of trade and economics.

If the next pandemic were to arise five years from now, there would have been breathing space to stimulate our drug and vaccine industries to limit the damage it would cause. But that requires urgent action now. As matters stand, a vaccine against a pandemic flu would not be ready until at least six months after a pandemic starts. Too late: by then the worst of the pandemic would already have happened.

A vaccine that can be produced more quickly demands a research effort akin to that for a strategic military weapon, not business as usual. We also need to be able to produce enough of such a vaccine to cope with the surge in demand during a pandemic. At present, the entire world production capacity can produce only enough doses for $\mathbf{4 5 0}$ million people. To stimulate an increase in capacity, we need health policies that boost demand for existing flu vaccines in ordinary years. The same goes for antiviral drugs.

But the worst-case scenario is that a pandemic starts within two years. We would have no vaccine and few drugs, and we would be dependent on governments and the WHO to try to extinguish the first outbreaks at source. That's why the first priority must be to prevent a pandemic emerging in the first place, by extinguishing the disease in animals.

\section{Time for action}

Unfortunately, the current situation does not bode well for the abilities of governments and international agencies to cope with this challenge. We should be monitoring in almost real time the genetic changes in the avian and human viruses that could herald the emergence of a pandemic strain, for example. But there is no international funding to help affected countries build decent and sustained surveillance programmes. And while outside researchers want data from affected countries, they aren't engaging enough in the meaningful collaboration needed to build trust and open sharing. The international community is not offering incentives, such as drugs for the Asian countries that would be in the front line of a pandemic. Combine this with the fact that countries are reluctant to share the few data they have because their analysis could affect their trade and economies, and the current mess in surveillance is hardly surprising.

Each human case that occurs in Asia is potentially a global threat. The international virology community needs to be permanently there, on the ground. We need to diagnose cases swiftly, and treat the patients and all their contacts immediately with antiviral drugs to try to kill the pandemic at source. To understand the genetics, and link this to the epidemiology and pathology of the virus, we need immediate sharing of all virus samples and data. None of this is happening adequately. National governments' performance is half-hearted, incomplete and far too slow. International organizations are working with their hands tied behind their backs, for bureaucratic and diplomatic reasons. In short, the level 
of current efforts is not commensurate with the threat we face.

This week, we focus on the issues in depth (see pages 390 and 399), and are providing a freely available, comprehensive collection of previous articles on the topic, not only from Nature but also from all other relevant Nature publications (see www.nature.com/nature/ focus/avianflu/index.html). Nature is also engaged in a collaboration with two other organizations. The journal Foreign Affairs will be publishing a survey of the policy aspects of avian flu and other pandemics in its next issue, to be published in late June. And, with both journals' involvement, the Royal Institution World Science Assembly is organizing a high-level international meeting chaired by Rita Colwell, former director of the US National Science Foundation, that is intended to bridge the gaps between science and policy.

Above all, greater top-level political oversight of the campaign is needed. The time for diplomacy and denial is over. It is time for advocacy and action.

\section{Europe's constitution}

\section{Referenda next week could derail the European project - with negative consequences for science.}

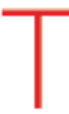
he people of France and the Netherlands will vote next week on whether their respective governments should ratify the proposed European constitution. Despite the traditional roles of both nations as stalwart supporters of greater European unity, their leaders have failed to generate much popular enthusiasm for the document, and both votes are expected to be close.

Research and innovation are critical to Europe's future, but have failed to emerge as an issue in the referendum campaigns. That's a shame, because their successful pursuit could hinge on the outcome of these votes.

The handful of pages in the lengthy constitution document that deal directly with research read blandly, and have inspired little enthusiasm in the scientific community. But there are aspects of the constitution that would herald significant changes in the science policy of the European Union (EU). Previous treaties, for example, have given the EU a remit to support research only as a means of bolstering industrial competitiveness. The constitution would authorize the EU to support science for its own sake.

The constitution would also tie up various loose ends in science policy. The European Research Council, for example, which is being established to support curiosity-driven research, has no legal basis in existing EU statutes, and might be contested by any member state that chose to oppose it. The constitution brings this badly needed new agency safely within the legal remit of the EU.

And the document gives the European Commission powers to remove "legal land fiscal obstacles" to scientific cooperation across borders. It also embraces the right to conduct scientific research "free of constraint", and upholds academic freedom in universities. These components would be steps towards a more open and democratic research system.

Additionally, the constitution

"The successful pursuit of research and innovation in Europe could hinge on the outcome of these votes."

is the only instrument on the table that will allow the EU to develop politically, by removing the veto powers of individual states on the Council of Ministers, and by further strengthening the European Parliament. If these reforms succeed, they will help to confer muchneeded legitimacy on EU institutions, and better enable the union to represent its 450 million people on the world stage.

Progress on this has been slow and cumbersome, and the verbosity of the proposed constitution reflects this challenge. Rejecting it will change nothing for scientists who find the EU to be remote and bureaucratic. Accepting it will, at least, open up opportunities for those who want to strengthen European science.

\section{Chemical biology is here}

\section{Nature and its new sibling Nature Chemical Biology reflect an important multidisciplinary trend.}

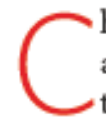
hemical biology is a recent addition to the scientific lexicon, and although its origin involves the use of small molecules to perturb and study biological function, it has recently grown to encompass a wide array of science at the interface between chemistry and biology. Like other multidisciplinary fields, chemical biology thrives because chemists and biologists have unique perspectives and skills that complement each other. For this reason, these collaborative efforts may be able to unravel complex biological problems.

The importance of this growing field can be seen in recent policy initiatives. In 2003, the creation of the US National Institutes of Health Roadmap (http://nihroadmap.nih.gov) led, for example, to the establishment of chemical-genomics screening centres and
PubChem (http://pubchem.ncbi.nlm.nih.gov), a cheminformatics database that is the small-molecule equivalent of PubMed. In addition, several of the recently appointed Howard Hughes Medical Institute investigators (www.hhmi.org/news/032105_list.html) have a significant chemical component to their research.

A year ago, Nature boosted its editorial resources specifically to respond to this trend. And this month our publishers have gone a major step further and launched Nature Chemical Biology (see www.nature.com/nchembio). As with all Nature journals, the new one represents a desire to meet the needs of a community without in any way reducing the commitment of Nature itself to publish high-quality papers in the field. Our aim is that Nature Chemical Biology will rapidly become the home of the strongest research for chemical biologists.

Chemical biology is often the lens that allows the biological community to see what chemists are capable of doing. It is our intention, in both Nature and Nature Chemical Biology, to illuminate the strengths and needs of these two communities and to stimulate new collaborations and scientific insights. 